\title{
Parental influence on childhood obesity: A review
}

\author{
Isabel Lin Tzou ${ }^{1 *}$, Nain-Feng $\mathrm{Chu}^{2,3}$ \\ ${ }^{1}$ Keck School of Medicine of University of Southern California, Los Angeles, USA; ${ }^{*}$ Corresponding Author: tzou@ $\underline{\text { usc.edu }}$ \\ ${ }^{2}$ Taitung Hospital, Department of Health, Taiwan \\ ${ }^{3}$ School of Public Health, National Defense Medical Center, Taipei, Taiwan
}

Received 4 November 2012; revised 14 December 2012; accepted 20 December 2012

\begin{abstract}
The issue of childhood obesity is expanding at an accelerated rate compared to previous generations. Both medical and societal conesquences have arisen from this predicament in children and adults. The significance of parental influence as a factor is of key interest in developing possible prevention programs. Three major categories of focus are parental control, attitudes, and behavior in association with childhood overweight and obesity. This comprehensive systematic and evidence-based review summarizes currently published results, as well as addresses gaps and flaws which should be included in future research on pediatric obesity and parental influence.
\end{abstract}

Keywords: Childhood Obesity; Childhood Overweight; Parental Influence; Eating Habits

\section{INTRODUCTION}

Obesity is a growing worldwide epidemic, threatening current and future generations alike. Currently, the obesity epidemic affects more than $17 \%, 12.5$ million, of American children, almost triple the prevalence rate of just the previous generation [1]. In 2010, over 42 million children, under the age of five, were affected by obesity, around 35 million of which are in developing countries [2]. While obesity-associated mortalities and morbidities occur more commonly in adults, the negative risk factors for diseases are significantly noticeable in childhood as well [3]. Without any changes made, these problems associated with obesity will only continue to increase at a rapid pace, making the expedient prevention of childhood obesity essential.

As adults, pediatric overweight and obesity is a predictor of adult obesity, increasing their likelihood of developing chronic diseases such as diabetes, heart disease, hypertension, and some cancers as well as body image disparagement [2,4-9]. For example, the evidence of car- diovascular risk factors caused by childhood overweight and obesity are predictors of adult cardiovascular morbidity and mortality [8]. Studies indicate that adolescent overweight in men is attributed to increased mortality from chronic diseases such as coronary heart disease, atherosclerosis, colorectal cancer and gout $[10,11]$. For women, adolescent overweight and obesity is correlated with arthritis decreasing functional limitations to perform daily activities and menstrual abnormalities, which is a risk factor for polycystic ovary disease (PCOD) [11,12]. The psychosocial consequences from childhood overweight and obesity also carry over in adulthood [12].

There are many adverse physical and mental effects of childhood obesity both acute and long-term. The effects of childhood obesity are quite similar to adults. For example, in children as young as five, physical symptoms include high blood pressure, dyslipidaemia, chronic inflammation, endothelial dysfunction, hyperinsulinaemia and increased blood clotting tendency - all of which are cardiovascular and insulin resistance risk factors leading to diseases such as cardiovascular disease and type II diabetes mellitus $[10,12,13]$. Obesity also causes seconddary pulmonary complication risk factors such as sleep apnea, asthma, and exercise intolerance limiting the child's physical activity status $[8,12-14]$. Children who are overweight and obese also suffer from psychosocial conesquences and tend to be discriminated and stereotyped as lazy, unhealthy, academically unsuccessful, socially inept, and non-hygienic causing negative self-image and selfesteem issues $[8,12,13]$.

Having a high-energy intake and low energy expenditure may attribute directly to obesity but unhealthy environments that promote eating are to blame as well [13, $15,16]$. Environmental cues influence a person's responsiveness to eat food starting from toddlerhood, when food deprivation is no longer the sole factor triggering the need to eat [7]. These environmental cues can be attributed to both family and social factors which influence the food intake of a child [17]. For instance, the home environment set by the availability of foods, preference for particular food items, portion size, cultural values, food preparation, mealtime structure and feeding styles 
are all first pre-determined for the child by parental influences at a young age where autonomy is not yet possible [7].

The purpose of this review is to summarize literature regarding parental influence and childhood overweight as well as propose suggestions for future research. Parental control, attitudes, and eating behaviors were examined in order to determine the parental impact on pediatric overweight and obesity.

\section{PARENTAL CONTROL}

Generally, parents serve as role models to determine what, when, and how to eat based upon the surrounding food environment and cultural lifestyle [16]. Parent-child interactions during feedings impose some type of control on the child's eating autonomy such as pressuring or restricting a child to and from certain foods [16]. Parental behaviors and influences used on feeding children include three main aspects: parenting style, home environment, and food availability [15]. Hypotheses based on these behaviors influencing children's weight status have engendered both positive and negative outcomes. Some studies show that parents may impose stricter food limitations in order to prevent their child from excess weight gain, while other studies show the opposite effect of con- trol causing the child to have the inability to regulate self-control of food intake leading to excess weight gain as seen in Table $\mathbf{1}[16,18,19]$.

Wardle et al. studied four common feeding styles seen in the development of childhood obesity: emotional feeding, instrumental feeding, prompting/encouragement to eat, and control over eating. Emotional feeding and instrumental feeding are seen to be associated with triggering eating cues in absence of hunger [17]. Excessive prompting and encouragement to eat are often associated with the parent's belief of heavy babies being healthier, or by a parent's enthusiasm to see the child eat certain foods. The last most common feeding type is control over eating, this includes restriction of certain foods which are believed to improve the child's diet and reduce the possibility of excess weight gain. Wardle et al. compared two groups of parents: overweight/obese and normal/lean weight mothers and their feeding styles for their children. The only difference in feeding styles between the two groups that was observed was the obese mothers exerted significantly less control over their children's food intake. The difference in control may have contributed to the difference in weights of children with obese parents versus normal weight parents [17].

Faith et al. divided their subjects between low-risk and

Table 1. Parental control in feeding practices on children's weight status.

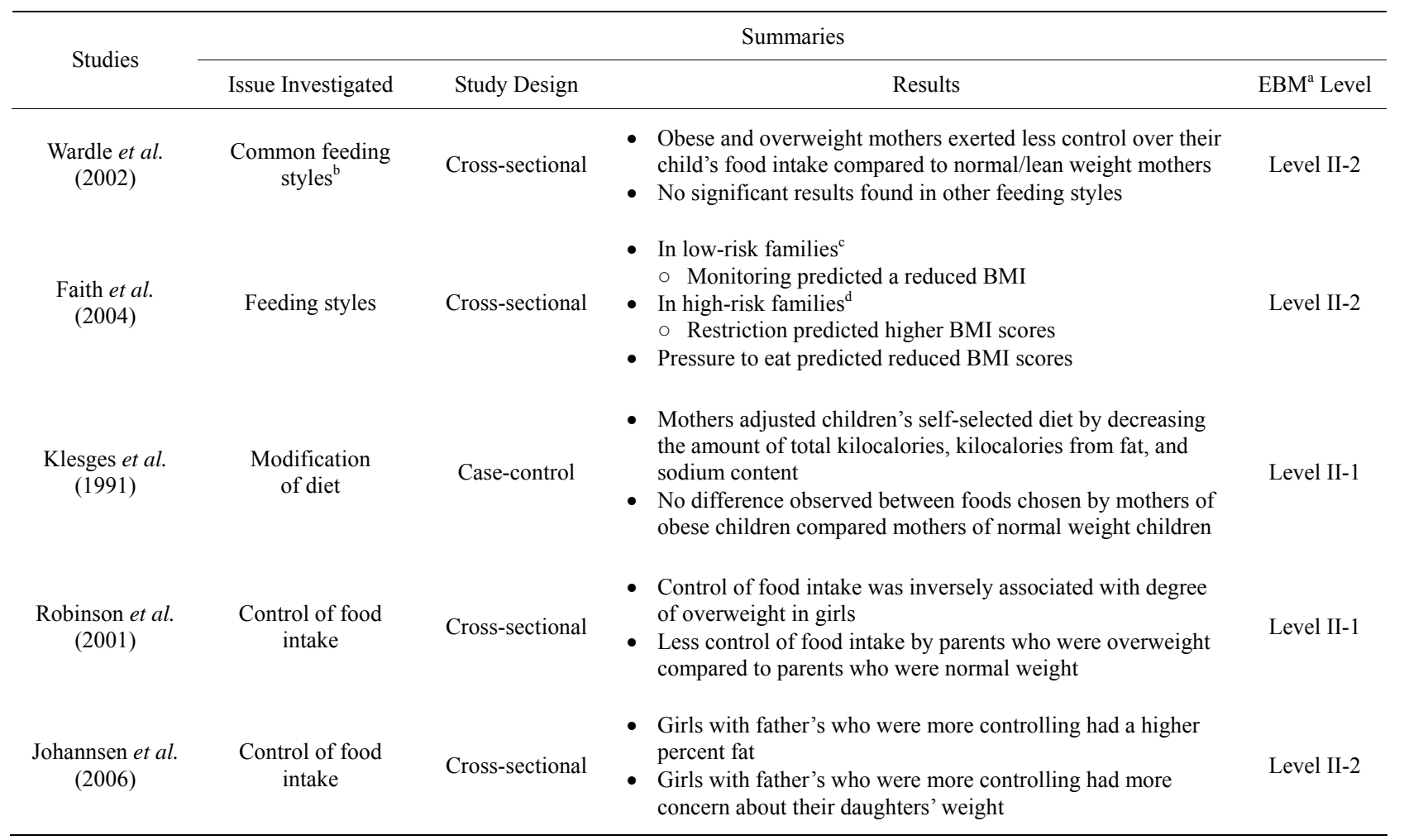

${ }^{a}$ Evidence-Based Medicine (EBM) levels based on US Preventative Services Task Force (USPSTF); ${ }^{b}$ Common feeding styles include: emotional feeding, instrumental feeding, prompting/encouragement to eat, and control over eating; ${ }^{\mathrm{c}}$ Low-risk: mothers had a pre-pregnancy weight $<33$ rd percentile; ${ }^{\mathrm{d}}$ High-risk: mothers had a pre-pregnancy weight $>66$ th percentile. 
high-risk families and investigated the feeding styles of monitoring, restriction, and pressure to eat on the childhood eating practices [20]. The results proved interesting and differed between the two groups. In the low-risk families, the feeding style of monitoring predicted a reduced BMI. However, in high-risk families, restriction of eating predicted higher BMI scores, while pressure to eat predicted reduced BMI scores. The increase and decrease of control as a general aspect did not have the same effect across either of the three feeding styles and in each of the separate risk groups [20].

Kleges et al. investigated the threat of parental influence on food selection in children and its association with obesity. The study centered on activities in which children were able to choose their own foods for lunch, ranging from low to high-nutritional level items [21]. The children were first able to choose any food items they wanted for lunch. For the second task, the children were asked to choose a new lunch in which they were told that their mother would inspect their food choices afterwards. For the last task, the mothers came in and were allowed to modify the lunches that their children themselves had selected. Between the first and second criteria, the children showed a drastic decrease in the amount of sugar content selected. However, when the mothers were able to adjust the food, they modified their child's lunch to have an overall less amount of kilocalories, fewer calories from fat and less sodium content. There was no significant difference found between the foods chosen by the mothers of obese children versus the mothers of normal weight children [21].

Robinson et al. aimed to determine the direct relationship of the parent's control of food intake with the child's degree of overweight [19]. Parental control over children's consumption of food was weakly inversely associated with the degree of overweight in girls, however no significant relationship was found in boys. The parents who reported greater control over the food intake of their child had daughters who were less overweight. Among the parents who were overweight, their control on their children's food intake was significantly less when compared to the other normal weight parents [19].

The Johannsen et al. study on control of food intake had significant results between the fathers and daughters [22]. Daughters with fathers who were stricter on the control of food intake had a higher percent fat. These fathers also had more concern about their daughter's weight. Contrary to their original hypothesis, the mothers' control over the children's eating was not significantly associated with the weight measures of either the daughters or the sons. The authors attributed this difference to the smaller sample size of fathers, however, their findings suggest that the fathers may play a role in the control of feeding practices [22].

\section{PARENTAL ATTITUDES}

Parental attitudes play an important role in determining the weight status of children. The attitudes and perceptions that the parents emit are helpful in predicting how the child's dietary habits and physical activity patterns are influenced as summarized in Table 2. If parents do not recognize childhood overweight and obesity as a health risk, they are less likely to acknowledge this as a problem, making prevention and treatment difficult [14].

Baughcum et al. unveiled three main beliefs held by mothers by examining maternal feeding practices on childhood obesity, specifically with low-income mothers. The mothers believed that heavier infants and toddlers represented a predictor of good health and successful parenting. They feared that their child was not getting enough to eat, causing them to introduce solid foods to their diets before the recommended age, and used food to reinforce appropriate behaviors; for example calming down a fussy baby with an extra bottle of food or a toddler's temper tantrum with treats [23]. The mothers were aware that they were going against nutritionist's advice, and admitted that their beliefs on introducing solid food at an early age stemmed mainly from their own mothers' advice. When a toddler with obese parents becomes overweight, it is a good indicator of the child developing obesity as an adult. Baughcum et al. believes that the mothers' perceptions on child feeding practices, especially increasing the amount of food eaten, increased the chances of their child developing obesity [23].

Johannsen et al. investigated the effects of mothers' and fathers' eating behaviors, child feeding practices and their own BMI versus their child's BMI and body fat percentage [22]. The authors measured the feeding attitudes of child's eating risk and future health concerns of the parents based off of the Child Feeding Questionnaire, $\mathrm{CFQ}$. The results showed that daughters and sons were more likely to be overweight if their mother's believed that they had risky eating habits, such as fussiness, overeating or undereating [22].

Mulder et al. conducted a cross-sectional study in Chile based upon maternal attitudes, child-feeding practices, and children's weight status in children [10]. Mothers of overweight children were significantly more concerned about the child's weight and perceived their children as higher weight category. On the contrary, mothers of normal weight boys used significantly more pressure to eat. The body mass indices of the sons were positively correlated with concern for child's weight and negatively with pressure to eat. The results concerning the body mass indices were only statistically significant in boys; however, it does provide key insight in the food relationship between the mother, child, and food [10]. 
Table 2. Parental attitudes on children's weight status.

\begin{tabular}{|c|c|c|c|c|}
\hline \multirow{2}{*}{ Studies } & \multicolumn{4}{|c|}{ Summaries } \\
\hline & Issue Investigated & Study Design & Results & EBM Level \\
\hline $\begin{array}{l}\text { Baughcum et al. } \\
\text { (1998) }\end{array}$ & Nutritional beliefs & Cross-sectional & $\begin{array}{l}\text { - Heavy babies are represent good health and parenting } \\
\text { - Feared their child was not getting enough to eat } \\
\text { - Used food to reinforce appropriate behavior } \\
\text { - Ignored nutritionist's advice }\end{array}$ & Level-III \\
\hline $\begin{array}{l}\text { Johannsen et al. } \\
\quad(2006)\end{array}$ & $\begin{array}{l}\text { Beliefs and } \\
\text { perceptions }\end{array}$ & Cross-sectional & $\begin{array}{l}\text { - Girls and boys were more likely to be overweight if their } \\
\text { mothers believed they had risky eating habits }\end{array}$ & Level II-2 \\
\hline $\begin{array}{l}\text { Mulder et al. } \\
\quad(2009)\end{array}$ & $\begin{array}{l}\text { Attitudes toward } \\
\text { child feeding } \\
\text { practices and weight } \\
\text { status }^{\mathrm{a}}\end{array}$ & Cross-sectional & $\begin{array}{l}\text { - Mothers of overweight children were more concerned with } \\
\text { child's weight } \\
\text { - Mothers of normal weight children used more pressure to eat } \\
\text { - BMI score was positively correlated with concern for child's } \\
\text { weight } \\
\text { - BMI score was negatively associated with pressure to eat }\end{array}$ & Level II-2 \\
\hline $\begin{array}{l}\text { Faith et al. } \\
\quad(2004)\end{array}$ & $\begin{array}{l}\text { Parental feeding } \\
\text { attitudes and styles } \\
\text { compared with BMI }\end{array}$ & Cross-sectional & $\begin{array}{l}\text { - In low-risk families } \text { b }^{\mathrm{b}} \text { perceived responsibility was negatively } \\
\text { associated with child's BMI } \\
\text { - In high-risk families } \text { : weight concern and perceived child } \\
\text { weight predicted an increase in child's BMI }\end{array}$ & Level II-2 \\
\hline $\begin{array}{l}\text { Etelson et al. } \\
\quad(2003)\end{array}$ & $\begin{array}{l}\text { Parental recognition } \\
\text { of obesity }\end{array}$ & Cross-sectional & $\begin{array}{l}\text { Parents of overweight children: } \\
\text { Did not differ in levels of concern of excess weight as a } \\
\text { health risk and knowledge of healthy eating patterns } \\
\text { Did differ in their accuracy and perceptions of their } \\
\text { child's weight }\end{array}$ & Level III \\
\hline
\end{tabular}

${ }^{a}$ Results only significant in boys; ${ }^{b}$ Low-risk: mothers had a pre-pregnancy weight $<33$ rd percentile; ${ }^{\mathrm{c}}$ High-risk: mothers had a pre-pregnancy weight $>66$ th percentile.

Faith et al. studied feeding attitudes and styles on a child's BMI as well and hypothesized that parental feeding attitudes and styles stay stable for at least two years, are associated with a child's BMI, and can predict the child's BMI [20]. When comparing these attitudes with obesity in high-risk families, child weight concern and perceived child weight were both positively associated with BMI. Among low-risk for obesity families, perceived responsibility was negatively associated with the child's BMI. Other predictive factors such as weight concern and perceived child weight showed an increased BMI while parental monitoring over a two-year period showed a reduced BMI [20].

Etelson et al. examined the parents' perspective of their own children's weight. The study aimed to examine the parents' recognition of obesity in their own children, knowledge of healthy eating, and excess weight as a health risk [14]. Based upon the questionnaire of these three criteria, generally the parents had a basic understanding of healthy eating patterns, such as limiting the intake of fast food to only once a week. For the perceived levels of concern on health risks for their child, excess weight ranked second, only behind passive smoking, among seven various risk conditions. However, when asked to assess their own child's weight status, only $48 \%$ of the parents correctly perceived their child's weight. The parents with overweight children had the lowest accuracy when it came to assessing their children, with only a $10.5 \%$ accuracy rate. The results of this study showed that although the parents seemed knowledgeable about healthy eating habits and the health risks of excess weight, more than half of the parents were unable to determine their own child's weight status [14].

\section{PARENTAL BEHAVIOR}

Many parents believe that obesity is an inherited problem, a genetic factor, which causes the excess weight gain, and do not consider how their own eating habits and the surrounding environment affect the child [14]. Genetic predisposition of childhood obesity of may be a factor, but the rising prevalence in childhood obesity proves that there must be some other factor that is contributing to this problem [10]. Factors such as the parents' eating habits and the environment that is surrounding the children should be considered as well as seen in Table 3 .

Johannsen et al. investigated the effects of the parents' eating behaviors, child feeding practices and body mass index on preschool aged children [22]. The study found no significant relationship between the parent eating behaviors and children's BMI and percentage fat. However, 
Table 3. Parental behavior and eating habits on children's weight status.

\begin{tabular}{|c|c|c|c|c|}
\hline \multirow{2}{*}{ Studies } & \multicolumn{4}{|c|}{ Summaries } \\
\hline & Issue Investigated & Study Design & Results & EBM Level \\
\hline $\begin{array}{l}\text { Johannsen et al. } \\
\qquad(2006)\end{array}$ & $\begin{array}{l}\text { Parental eating behaviors } \\
\text { and weight status } \\
\text { compared to child's BMI }\end{array}$ & Cross-sectional & $\begin{array}{l}\text { - No relationship between parental eating behaviors and } \\
\text { children's BMI } \\
\text { - Mothers' BMI is strong predictor of children's percent } \\
\text { fat and BMI } \\
\text { - Mothers' and fathers' weight history is strongly related } \\
\text { to daughter's BMI }\end{array}$ & Level II-2 \\
\hline $\begin{array}{l}\text { Birch \& Fisher } \\
\text { et al. }(2000)\end{array}$ & $\begin{array}{l}\text { Shared and non-shared } \\
\text { family environment: } \\
\text { mother's perceptions and } \\
\text { dietary restraint on daughts }\end{array}$ & Cross-sectional & $\begin{array}{l}\text { - Maternal BMI predicted daughters' relative weight } \\
\text { - Mother's dietary restraint and perceptions of daughts' } \\
\text { risk of overweight predicted maternal child-feeding } \\
\text { practices-predicting daughters' eating and relative } \\
\text { weight }\end{array}$ & Level III \\
\hline $\begin{array}{l}\text { Campbell et al. } \\
\text { (2007) }\end{array}$ & $\begin{array}{l}\text { Mother's diet and home } \\
\text { environment }\end{array}$ & Cross-sectional & $\begin{array}{l}\text { Mothers' intake of high-energy fluids, snacks and } \\
\text { takeout foods is associated with son's intake of same } \\
\text { foods } \\
\text { - Mothers' intake of high-energy fluids is associated } \\
\text { with daughter's intake of same foods } \\
\text { - Food availibility of unhealthy foods were positively } \\
\text { associated with daughters' consumption of high-energy } \\
\text { fluids, snacks and son's savory snacks }\end{array}$ & Level III \\
\hline $\begin{array}{l}\text { Brown \& Ogden } \\
(2004)\end{array}$ & Parental modelling & Cross-sectional & $\begin{array}{l}\text { - Significant correlation between unhealthy snack intake } \\
\text { between the parents' and childrens' diet } \\
\text { - Positive correlation between parents' and childrens' } \\
\text { internal motivations for eating and body dissatisfaction } \\
\text { - Parents made greater attempts on control of childern's } \\
\text { diet when they had higher intake of food } \\
\text { - Parents who used food as a means of control reported } \\
\text { higher body dissatisfaction }\end{array}$ & Level II-2 \\
\hline
\end{tabular}

the mother's BMI was proved to be an extremely strong and independent predictor of children's percentage fat and BMI. Mothers who had a higher BMI reported having a greater concern for their child's future health. This specific criterion explains more variance in the child's weight status outcomes than the parent feeding factors. It was also shown that the mother's weight history was strongly related specifically to their daughter's BMI, leading the researchers to hypothesize a possible genetic influence [22].

Birch \& Fisher measured the mother's influence on their daughter's eating and weight through shared and non-shared family environments [24]. In order to predict the child-feeding practices of the daughter, the mother's own dietary restraint and perceptions of their daughter's risk of overweight were used. Statistically significant data showed that the relative weight between the daughter and mother was associated. However more importantly, the results showed a feedback loop: as the daughters' relative weight increased, the mother's perceptions of the daughters' overweight and concerns about the daughter's overweight risk increased. These perceptions influenced the mother's restriction and eating habits of their daughter, which in turn affected their daughter's weight status. These perceptions were then measured against their daughter's weight outcome. An important result showed the non-shared environmental influence of the maternal control and their daughter's eating habits and relative weight. The result of the influence and restrictions that were used was predicted by the mother's perception of their daughter's overweight risk [24].

Campbell et al. to show the associations between the home environment, with a specific focus on parental eating behaviors and food availability, on the frequency and types of food eaten by the adolescents [15]. The study showed that the mother's intake of high-energy fluids, sweet and savory snacks, and take-out foods were positively correlated with the son's intake of those same foods. Similarly, the mother's intake of high-energy fluids was positively associated with daughter's intake of those drinks. The availability of these unhealthy foods in the home environment was further positively correlated with daughters' consumption of high-energy drinks, sweet and savory snacks, and the intake of the sons' savory snack [15].

Brown \& Ogden focused on parental modeling and its 
impact on a child's eating attitudes and behavior [25]. Modeling occurs through observational learning and it was reflected in their study. There was a significant correlation between the unhealthy snack intake, such as chocolates, crisps, and sweets, of the parents and the children, indicating that the parents' diet was associated with a similar diet by the children. There was also a significant positive correlation between the parents' and children's internal motivations for eating and body dissatisfaction [25].

\section{DISCUSSION}

From previous studies, parental influence is a key risk factor for childhood weight gain and obesity. It can control the obesegenic environment by affecting the child's dietary habits, physical activity, the accessibility and availability of foods and food-related processes [26]. Since parents provide the contextual environment, addressing this issue is of clinical and public health relevance as obesity is persistently and rapidly increasing.

While extensive research has established associations of childhood obesity and disease prevalence, there is still research needed regarding how childhood obesity comes about environmentally. Due to the inconsistency and lack of the current research, it is difficult to determine the causal parental agent of childhood weight. In this review we cannot accurately determine the directional analysis of attitudes, control and behavior and its relationship between child-feeding practices. Furthermore, there is also a question of whether the parental attitudes, control and behavior are interrelated or not, and their relative importance to each other. In order to assign a causal relationship between parental child-feeding practices and childhood obesity, there needs to be more longitudinal studies and clinical trials done $[5,10]$. This scarcity of information provides a challenge for the prevention of childhood obesity using parents as an environmental factor. It begs the question of where a prevention program would be most effective: control, attitudes, or behavior.

As shown in the aforementioned studies, these countering results prove to be a challenge in determining the directional associations of parents as a key factor and its effect on the child-feeding practices. Future research needs to elaborate more on the bi-dyadic relationship between parental influence and childhood overweight and obesity to determine their relationship [5,24]. This will make prevention more effective if the program is targeted and tailored for a specific aspect. Many believe that the responsibility for the prevention and treatment of child obesity falls upon the parents, and it is their responsibility to correct their own attitudes toward childhood obesity as they are related to the health of their child [27]. Therefore we must determine its predictability value when assessing the relationship of childhood weight gain and other environ- mental factors.

There are many research gaps that need to be addressed regarding parental habits and childhood weight gain. Research ideas regarding the issue of childhood obesity includes stratifying childhood weight gain on not only parental feeding practices but also by gender of the parent, age group, diet, home environments, racial and ethnic differences, socio-economic status, interactions with siblings, other adult caretakers, physical activity level, life-style and more $[6,11,15,16,19,23,24]$. Another rather important factor includes the geographical location of each population - this is a good indicator of the cultural beliefs and attitudes toward feeding and eating and needs to be taken in account when implementing any future prevention programs.

\section{CONCLUSIONS}

From this review we identified current published results on pediatric obesity and parental influence, as well as research gaps and flaws that should be addressed in future research. Childhood overweight and obesity has both short term and long-term consequences, such as the development of risk factors for future chronic diseases. Childhood obesity affects multiple organ systems, and these can develop not only into physical problems, but also psychosocial consequences leading to increased adult morbidity and mortality $[8,10,13]$. Priority values need to be assigned in order to focus both research and programs on how to stop and possibly reverse the negative global impact of childhood obesity. This in turn will lower the consequent morbidities due to these related chronic diseases in adulthood caused by childhood.

In order to develop preventative measures, a source of childhood overweight and obesity needs to be identified, which is lacking in current research. Much of previous research is inconsistant, with no direct correlation between parent influence and childhood obesity. The longer the problem persists, the more children are affected. This will cause more financial resources to be utilized inefficiently due to the chronic problems that are associated with weight gain and obesity.

Lastly, obesity is an important public health problem that needs to be addressed for future generation. Studies show that childhood and adolescent obesity play a predictive role in subsequent adult obesity and future comorbidities. Prevention methods, which focus on childhood obesity and effective treatment for overweight children are glaringly important [9]. The current treatments for childhood obesity are similar to the treatments for adults: focusing on behavior, psychological and/or medical interventions [27]. Research on predictive factors, such as parental influence, can be used to develop effective prevention programs. This does not just end with 
childhood - the problem will continue into adulthood and future generations alike if these habits are not corrected.

\section{REFERENCES}

[1] Center for Disease Control and Prevention (2012) Overweight and obesity.

http://www.cdc.gov/obesity/childhood/data.html

[2] World Health Organization (2012) Childhood overweight and obesity. http://www.who.int/dietphysicalactivity/childhood/en/

[3] Division of Nutrition, Physical Activity and Obesity, National Center for Chronic Disease Prevention and Health Promotion. (2012) Basics about childhood obesity. http://www.cdc.gov/obesity/childhood/basics.html

[4] Birch, L.L., Faith, M.S., Francis, L.A., Scanlon, K.S. and Sherry, B. (2004) Parent-child feeding strategies and their relationship to child eating and weight status. Obesity Research, 12, 1711-1722. doi:10.1038/oby.2004.212

[5] Birch, L.L. (2006) Child feeding practices and the etiology of obesity. Obesity, 14, 343-344. doi:10.1038/oby.2006.45

[6] Deckelbaum, R.J. and Williams, C.L. (2001) Childhood obesity: The health issue. Obesity Research, 9, 239-243. doi:10.1038/oby.2001.125

[7] Patrick, H. and Nicklas, T.A. (2005) A review of family and social determinants of children's eating patterns and diet quality. Journal of American College of Nutrition, 24, 83-92.

[8] Reilly, J.J., Methven, E., McDowell, Z.C., Hacking, B., Alexander, D., Stewart, L. and Kelnar, C.J.H. (2003) Health consequences of obesity. Archives of Disease in Childhood, 88, 748-752. doi:10.1136/adc.88.9.748

[9] Whitaker, R.C., Wright, J.A., Pepe, M.S., Seidel, K.D. and Dietz, W.H. (1997) Predicting obesity in young adulthood from childhood and parental obesity. New England Journal of Medicine, 337, 869-873. doi:10.1056/NEJM199709253371301

[10] Mulder, C., Kain, J., Uauy, R., and Seidell, J.C. (2009) Maternal attitudes and child-feeding practices: Relationship with the BMI of Chilean children. Nutrition Journal, 8, 37. doi:10.1186/1475-2891-8-37

[11] Power, C., Lake, J.K. and Cole, T.J. (1997) Measurement and long-term health risks of child and adolescent fatness. International Journal of Obesity, 21, 507-526. doi:10.1038/sj.ijo.0800454

[12] Dietz, W.H. (1998) Health consequences of obesity in youth: Childhood predictors of adult disease. Pediatrics, 101, 518-525.

[13] Ebbeling, C.B., Pawlak, D.B. and Ludwig, D.S. (2002). Childhood obesity: Public-health crisis, common sense cure. The Lancet, 360, 473-482. doi:10.1016/S0140-6736(02)09678-2

[14] Etelson, D., Brand, D.A., Patrick, P.A. and Shirali, A. (2003) Childhood obesity: Do parents recognize this health health risk? Obesity Research, 11, 1362-1368. doi:10.1038/oby.2003.184

[15] Campbell, K.J., Crawford, D.A., Salmon, J., Carver, A., Garnett, S.P. and Baur, L.A. (2007) Associations between the home food environment and obesity-promoting eating behaviors in adolesence. Obesity, 15, 719-730. doi:10.1038/oby.2007.553

[16] Savage, J.S., Fisher, J.O. and Birch, L.B (2007) Parental influence on eating behavior: Conception to adolesence. The Journal of Law, Medicine, \& Ethics, 35, 22-34. doi:10.1111/j.1748-720X.2007.00111.X

[17] Wardle, J., Sanderson, S., Guthrie, C.A., Rapoport, L. and Plomin, R. (2002) Parental feeding style and the inter-generational transmission of obesity risk. Obesity, 10, 453462. doi: $10.1038 /$ oby. 2002.63

[18] Benton, D. (2004) Role of parents in the determination of childrens' food preferences. International Journal of Obesity, 28, 858-869. doi:10.1038/sj.ijo.0802532

[19] Robinson, T.N., Kiernan, M., Matheson, D.M. and Haydel, K.F. (2001) Is parental control over children's eating associated with childhood obesity? Results from a population-based sample of third graders. Obesity, 9, 306-312. doi:10.1038/oby.2000.38

[20] Faith, M.S., Berkowitz, R.I., Stallings, V.A., Kerns, J., Storey, M. and Stunkard, A.J. (2004) Parental feeding attitudes and styles and child body mass index: Prospective analysis of gene-environment interaction. Pediatrics, 114, 429-436. doi:10.1542/peds.2003-1075-L

[21] Klesges, R.C., Stein, R.J., Eck, L.H., Isbell, T.R. and Klesges, L.M. (1991) Parental influence on food selection in young children and it's relationships to childhood obesity. The American Journal of Clinical Nutrition, 53, 859-864. doi:10.1093/her/cyg040

[22] Johannsen, D.L., Johannsen, N.M. and Specker, B.L. (2006) Influence of parents' eating behaviors and child feeding practices on children's weight status. Obesity, 14, 431-439. doi:10.1038/oby.2006.57

[23] Baughcum, A.E., Burklow, K.A., Deeks, C.M., Powers, S.W. and Whitaker, R.C. (1998) Maternal feeding practices and childhood obesity: A focus group of low-income mothers. Archives of Pediatrics \& Adolescent Medicine, 152, 1010-1014.

[24] Birch, L.L. and Fisher, J.O. (2000) Mother's child-feeding practices influence daughters' eating and weight. The American Journal of Clinical Nutrition, 71, 1054-1061.

[25] Brown, R. and Ogden, J. (2004) Children's eating attitudes and behaviour: A study of the modelling and control theories of parental influence. Health Education Research, 19, 261-271. doi:10.1093/her/cyg040

[26] Golan, M. and Crow, S. (2004) Parents are key players in the prevention and treatment of weight-related problems. Nutrition Reviews, 62, 39-50. doi:10.1301/nr.2004.jan.39-50

[27] Schwartz, M.B. and Puhl, R. (2003). Childhood obesity: A societal problem to solve. Obesity Reviews, 4, 57-71. doi:10.1046/j.1467-789X.2003.00093.x. 